\title{
BROCKHAMPTON:
}

\section{Social Advocacy and Diversity in Rap Music}

\author{
Ndidi Opara ${ }^{1}$
}

${ }^{1}$ Lake Washington High School, Kirkland, WA, USA

\section{$\underline{\text { ABSTRACT }}$}

BROCKHAMPTON is a diverse, multiracial rap group that has recently garnered rapidly increasing popularity and influence in the rap industry. Because of this, I wanted to determine if the popularity of the group's SATURATION trilogy was affected by the content matter they addressed and how that intersected with the American color line in music marketing. With the research question, "To what extent does the race of a BROCKHAMPTON member and the advocacy they utilize, whether it be pro-social or anti-social advocacy examined through the usage of corresponding social themes, influence the popularity of a given song from BROCKHAMPTON's SATURATION trilogy?", this study found that it was influenced to a minor extent, with no strong correlation found between race and social themes discussed, or between popularity and the dominant thematic category of a song.

\section{Context}

I have always struggled with the stigma on that rap is an aggressive, violent, and rageful genre. When I listen to rap, I hear social themes and messages that are underneath the sound of the music. However, I have realized that people often do not hear the same messages I do. I also realized that people do not choose to interpret rap music the same way I do. I realized that I had forgot that the perception of rap as a multi-layered genre is not one that often comes to the untrained ear. Along with this, I noticed that media and the academic world often discards the positive, advocating side of Hip-Hop. I hope to address this with my research, using rap group BROCKHAMPTON to examine the interpretation of rap and its content.

\section{BROCKHAMPTON}

BROCKHAMPTON is a 'boy band' rap collaborative based out of Texas. The original members met on online forum KanyeToThe, where the front man Kevin Abstract asked: "Anyone wanna make a band?" (Mathus, 2018). Since their 2012 genesis BROCKHAMPTON has risen to Hip Hop stardom with their SATURATION trilogy. The three albumsSATURATION I, SATURATION II AND SATURATION III - all became extremely popular when released during 2017 to 2018 (Jenkins, 2018). The group continues to become increasingly popular, especially after their social media hit "SUGAR", which peaked at \#66 on Billboard's Hot 100 Chart (Billboard, 2020). Some attribute this popularity to the appeal of the cultural capital of the group. BROCKHAMPTON proves itself to be an extremely diverse group, with "black, white, gay, straight, African, South Asian, Irish, and Latin members" (Jenkins, 2018). Because of this, BROCKHAMPTON is appealing to multiple audiences, despite the fact that rap music is typically regarded as a 'African American' genre-meaning regarded primarily for African American audiences and created primarily by African Americans. BROCKHAMPTON's appeal and racial diversity has made it an anomaly in the Hip-Hop world, justifying the examination of BROCKHAMPTON within this study. 


\title{
Hip Hop in Academic Literature
}

\author{
Defining Hip-Hop
}

The academic world has expanded the meaning of Hip-Hop far beyond poetry set to music, but now, to a cultural phenomenon (Dunbar, 2007). Researchers like Dunbar and Alridge even cite Hip-Hop as an expression of 'blackness', as well as a driving influence amongst African American youth. American sociologist Alridge elaborates on this by asserting that rap is merely one of the vessels to convey messages to the Hip-Hop community (Dunbar, 2007; Alridge, 2003). Researchers Miller, Hodge, Coleman, and Chaney agree with this, and go as far as to assert that Hip Hop culture communicates messages "through the five cultural modes of rap music (oral), turntablism or "DJing" (aural), breaking (physical), graffiti art (visual) and knowledge (mental)" (Miller, Hodge, Coleman, \& Chaney, 2014). Moreover, the assessment of Hip-Hop as a culture, not just a genre, is consistent in most literature. Therefore, within the context of this study, HipHop is defined as the larger culture surrounding the musical genre and rhythmic style of rap. Historically, Hip-Hop has been used to convey social messages and as a form of advocation (Dunbar, 2007). However, literature frequently identifies varying levels of positive advocating themes in Hip-Hop.

\section{Theorizing Advocacy}

Advocacy in rap music could be impactful. Pinn draws off of this idea in his 1999 peer-reviewed article "'How Ya Livin': Notes on rap music and social transformation", where he analyzes differences between the content of Progressive rap and Gangsta rap and their potential for social transformation. Pinn defines Progressive rap as rap that expresses "a lamentation of present conditions, the condemnation of misconduct and its resulting destruction [...]", and Gangsta rap as "a response to absurdity and meaninglessness which suggests social transformation through the mimicking and/or signifying of certain ideologies and behaviors". Pinn found that both types of rap, despite Gangsta raps' expression of negative attitudes, work towards combatting oppression. Pinn also found that the success of all rap, no matter how you categorize it, is unknown, due to the quickly changing nature of Hip-Hop and its evergrowing influence (Pinn, 1999). This unpredictable nature of Hip-Hop's success in carrying advocacy is an observation that characterizes a theoretical approach to advocacy in Hip-Hop. However, research has also largely found that in rap, advocacy absorbed by the listener is dependent on the content, subject, and relatability of the music.

\section{Practicing Advocacy in Hip-Hop}

There are many examples where an album has contained advocating messages in its content. Kendrick Lamar's To Pimp A Butterfly (TPAB), an album that has become a canonical piece of rap literature since its release in 2015, has been accredited for its messages on the African American experience (Blum, 2016). Despite the influence of albums like TPAB, content-analyses on rap music and music videos have found that when practicing advocacy, they may advocate for negative social beliefs that go against current social efforts. For example, a 2009 content analysis found that rap music videos promote Eurocentric features in women that cause social esteem issues in African American women (Conrad, Dixon, \& Zhang, 2009). This, combined with Hip-Hop's influence, has been viewed as potentially dangerous by researchers like Rutherford, who argues that Hip-Hop has influenced youth through negative images that promote abiding by a "criminal-minded value system that praises confrontation, aggressiveness and crime and shuns humility, kindness and legality" (Rutherford, 2005). Accredited American culture theologists Epps and Dixon further advance the notion of different types of advocacy by defining pro-social and anti-social rap. Pro-social stands to promote positive intercommunity interaction, while anti-social rap presents rap that may be harmful to the psyche of its listener through negative social themes (Epps \& Dixon, 2017, p. 467). This study will also use these definitions of pro-social and anti-social rap. Multiple Researchers have contributed arguments that explain both the pro-social 
and anti-social sides of rap. However, there are notable patterns within their research findings: while an album with content like Lamar's $T P A B$, meaning the album advocates may be identified as pro-social, the majority of rap albums have been identified as anti-social (Blum, 2016; Epps et. al 2017). Rarely has an album been identified as a mixture of the two. However, as Hip-Hop and its surrounding media it continues to change rapidly, researchers have struggled to keep up. Consequently, rap and its potential for advocacy have yet to be considered in media today. However, HipHop has failed to diversify itself and change as media has.

\section{Hip-Hop and Race}

Hip-Hop is still aimed largely towards an African American demographic because the artists behind Hip-Hop are primarily African American. This characteristic is not unique to Hip-Hop- genres that are primarily African American have now been regarded as genres just for African Americans by the color line in music marketing. Barretta (2017) elaborates in his peer-reviewed article, "Tracing the color line in the American music market and its effect on contemporary music marketing”. Genres like blues, jazz, and hip-hop are now regarded as music for primarily African American audiences because of the way the music market previously segregated African American and Caucasian music. By segregating the two, music companies could capitalize off authenticity based off the race of the artist, constituting the color line in music. Barretta claims that this color line could still influence music marketing today (Barretta, 2017). However, Gallagher's "Color-Blind Privilege: The Social And Political Functions Of Erasing The Color Line In Post-Race America" asserts that though this color line exists, the new "colorblind' society view-that is, believing that race has no affect at all on society status rather than acknowledging systemic oppression-has allowed for a separation of race from Hip-Hop. Because of this separation, the white community has allowed itself to connect more with Hip-Hop, removing racial barriers, and consequently, the effect of the color line (Gallagher, 2003). As the effect of the color line diminishes, it has been met with mixed response. Researchers like McLeod recognize the connotated threat that white culture poses to black culture, especially within Hip-Hop (Mcleod, 2017). However, researchers like Travis recognize the positive influence Hip-Hop can have in shaping the lives of youth, regardless of race (Travis, 2013). Despite this growing debate over the color line and its development, research has rarely explored how artists that aren't African American, and their audience are affected by their race and the color line.

Generalizations and literature about rap have often disregarded one, any middle ground between anti-social and pro-social rap in larger bodies of rap work, and two, the effect the color line in music has had on the way HipHop is academically analyzed. This study seeks to address these gaps in the understanding of Hip Hop by analyzing BROCKHAMPTON's SATURATION trilogy. Examining this trilogy specifically provides an effective parameter for research by using a current, predefined data set. To address these gaps, it is apparent that the levels of advocacy must be analyzed within the scope of lyrical potential while factoring in race in order to garner a better understanding of HipHop and its influence.

\section{Definitions}

The following are terms that will be employed frequently throughout the body of this study.

Social themes: advocating messages in rap music that are often categorized by the content and manner of the advocacy. For example, 'Religion and Spirituality' or 'Criminal Activity' (Epps \& Dixon, 2017 p. 467).

Advocacy: expressing support of a cause, belief system, or behavior (Advocacy, 2020). For this study, advocacy in rap is defined as the glorification, support, or citation of a social theme.

Thematic Categories: groups of themes that are either anti-social or pro-social. 
Pro-Social Rap: rap that utilizes social themes that promote positive intercommunity interactions (Epps \& Dixon, 2017 p. 467). This rap advocates for pro-social behaviors, causes, and belief systems.

Anti-Social Rap: rap that utilizes social themes that promotes negative intercommunity interactions that may be harmful to the psyche of its listener (Epps \& Dixon, 2017 p. 467). This rap advocates for anti-social behavior, causes, and belief systems.

Manner of Advocacy: whether the advocacy is pro-social or anti-social.

\section{Research Questions and Hypotheses}

Using the following methodology, I intend to answer this question and these sub-questions of inquiry: To what extent does the race of a BROCKHAMPTON member and the advocacy they utilize, whether it be pro-social or anti-social advocacy examined through the usage of corresponding social themes, influence the popularity of a given song from BROCKHAMPTON's SATURATION trilogy?

a. Does the manner of advocacy—whether it be pro-social or anti-social—have any effect on the popularity of a given song?

b. Is there any correlation between the manner of advocacy performed in a song and the race that performs it?

Prior to completing this study, my initial hypotheses in response to the preceding questions are: My new understanding of Hip-Hop leads me to hypothesize that the race of a rap artist and the advocacy they utilize will influence the popularity of a given rap song to a great extent.

a. Although it is unclear if the advocacy utilized in the SATURATION trilogy will predominately be anti-social or pro-social, I hypothesize that the most popular songs will either be predominately anti-social with the least popular songs being pro-social or vice versa.

b. I hypothesize a strong relationship between the kinds of themes utilized by the performing artist and their race exists.

\section{Methodology}

This study will use a comparative content analysis with three factors: a thematic analysis of the lyrics of the SATURATION trilogy, an examination of the leading race of a song, and the popularity of each song.

To analyze the lyrics, I did a thematic content analysis on each of the three SATURATION albums, with each song being a sample. This method is like the one used by Epps and Dixon in their aforementioned peer reviewed article. When I annotated the lyrics for evident social themes, I used the following parameters and guidelines:

a. Lyrics were retrieved from Genius Music, a music media platform that publishes lyrics by Genius users. These users can also be the artist themselves. Potential disparities or errors in the lyrics were deemed unrealistic, as each BROCKHAMPTON song lyric page had multiple transcribers and consequently, multiple rounds of revision (Genius Media Group Inc. 2020).

b. All SATURATION songs were included in the data sample.

c. Variances in the platform for annotation i.e. whether a person chooses to annotate digitally or with paper and pen are negligible. For this study, I chose to annotate using a Surface Laptop and the Surface Pen, a computer stylus. Genius Lyric pages for each song were printed to PDF and then printed to Microsoft OneNote, where they were then annotated. Annotations were stored digitally, and the method of annotation was consistent.

d. SATURATION lyrics in Spanish were translated to English with online Spanish-English translator SpanishDict (SpanishDict. 2020). Translator choice was consistent. 
e. Social themes that I identify in the lyrics will be linked to the following themes. Epps and Dixon's themes that they identified in their article were grouped into larger categories based off of thematic similarities. Some of the themes were self-generated, sourced from a personal understanding of historical context. The table 1 displays the larger thematic groups used with generated themes italicized.

f. Social themes that I identify must be directly apparent in the music. In other words, social themes noted in the lyrics cannot be metaphoric or symbolic. This guideline was used to stimulate what the average listener hears when listening to any rap song. The figure 1 is an example of this guideline in practice.

Table 1. Social Themes used in Study with Categorization

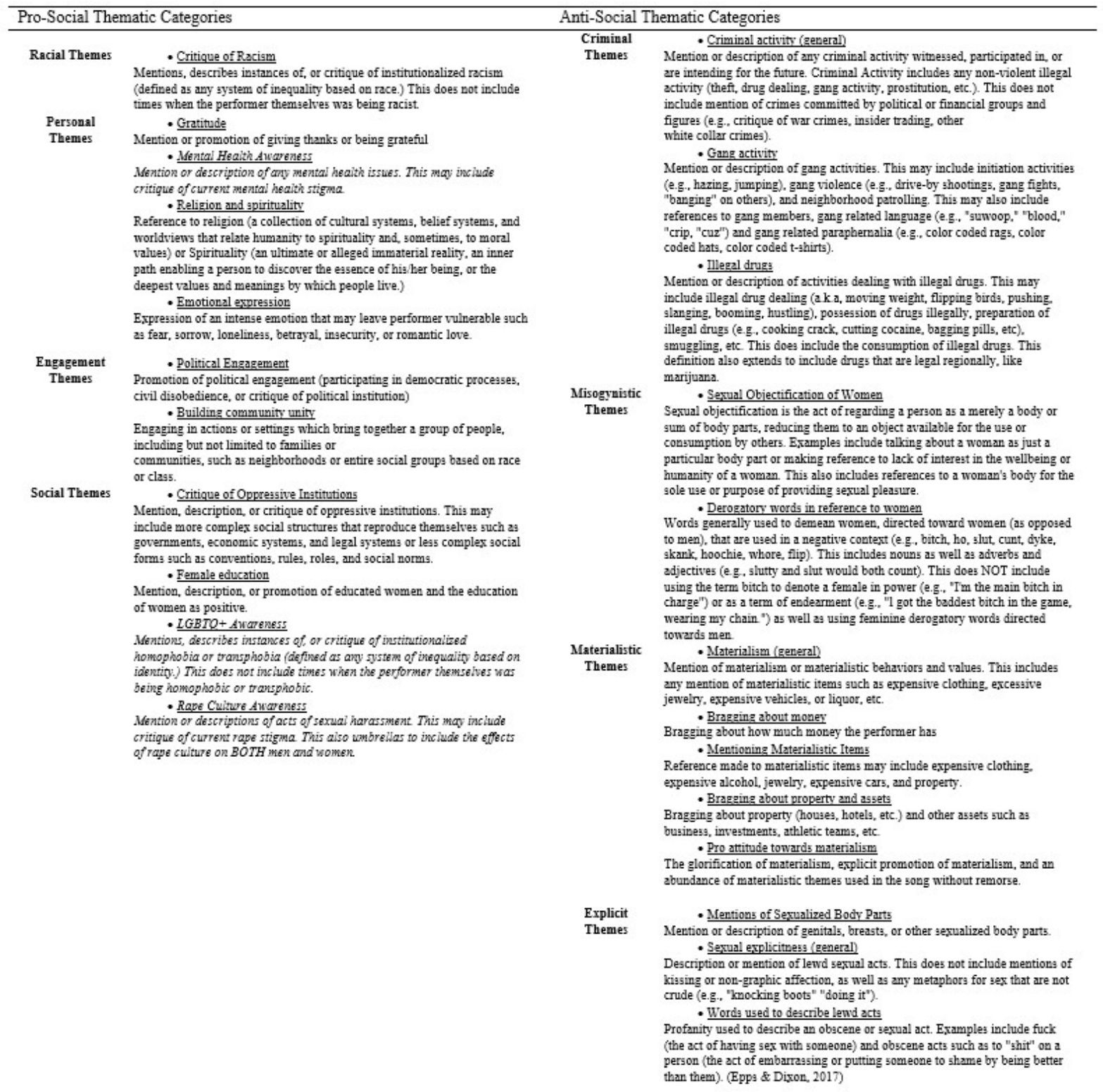




\section{GOLD Lyrics}

[Chorus: Kevin Abstract]

Keep a gold chain on my neck

Ely as a jet, boy, better treat me with respect

Keep a gold chain on my neck

Fly as a jet, boy, better treat me with respect

(Keep a gold chain) Keep a gold chain on my neck

Fly as a jet, boy, better treat me with respect

(Keep a gold chain) Keep a gold chain on my neck

Fly as a jet, boy, better treat me with respect

[Verse 1: Matt Champion]

Rock the boat like a one-eyed pirate

Rick James, I get glitter on my eyelids

2 A.M., 85 on the highway

Whole world get a little misguided

"Keep a gold chain on my neck" can be counted as a "Materialistic" theme because it speaks directly of wealth and material possession.

The lyric "Rick James, I get glitter on my eyelids cannot be associated with any theme. Even though it can be interpreted as a contradiction of traditional masculinity, the line says nothing overt about its intentions.

Figure 1. Exemplifying Direct Identification in Lyrics

g. The albums were annotated one at a time, in released order-meaning SATURATION I, SATURATION II, then SATURATION III. The songs were annotated in the order of the album track list published on Genius Music.

h. Location and time of which I decided to annotate had little effect on the results of my annotations.

i. When analyzing each song, I used the line structure that Genius Music provided to count any line that contained one of the social themes. I also noted the member who contributed the most to each theme in each song. This was done to observe any correlations between race and theme.

j. A line could have had multiple social themes attributed to it if multiple themes were present.

$\mathrm{k}$. If the amount of lines a member contributes to a theme is equal to that of another member for a given theme, multiple members can be attributed to one theme in a given song.

1. These line counts were aggregated into a count for the presence of each social theme in a song. This count (variable $\mathrm{x}$ in the following table) was divided by the total lines in a song to determine the concentration of a theme in the song. Along with this, this count was divided by the number of lines that had a theme identified to determine the concentration of a theme out of all of the themes identified. Please refer to figure 2 for sample data. 


\begin{tabular}{|c|c|c|c|c|c|}
\hline CASH & Theme & $\begin{array}{l}\text { Anti- } \\
\text { Social } \\
\text { vs. Pro- } \\
\text { Social? }\end{array}$ & $\frac{x}{\text { total lines in song }}$ & $\frac{x}{\text { \# of identified themes }}$ & \begin{tabular}{|l|} 
Main artist \\
behind
\end{tabular} \\
\hline & $\begin{array}{l}\text { Critique of Racism } \\
\text { Gratitude } \\
\text { Mental Health Awareness } \\
\text { Religion and spirituality } \\
\text { Emotional expression } \\
\text { Political Engagement } \\
\text { Building community unity } \\
\text { Critique of Oppressive Institutions } \\
\text { Female education } \\
\text { LGBTQ+ Awareness } \\
\text { Rape Culture Awareness } \\
\text { Criminal activity (general) } \\
\text { Gang activity } \\
\text { Illegal drugs } \\
\text { Sexual Objectification of Women } \\
\text { Derogatory words in ref. to women } \\
\text { Materialism (general) } \\
\text { Bragging about money } \\
\text { Mentioning Materialistic Items } \\
\text { Bragging about property and assets } \\
\text { Pro attitude towards materialism } \\
\text { Mentions of Sexualized Body Parts } \\
\text { Sexual explicitness (general) } \\
\text { Words used to describe lewd acts }\end{array}$ & $\begin{array}{l}\text { PS } \\
\text { PS } \\
\text { PS } \\
\text { PS } \\
\text { PS } \\
\text { PS } \\
\text { PS } \\
\text { PS } \\
\text { PS } \\
\text { PS } \\
\text { AS } \\
\text { AS } \\
\text { AS } \\
\text { AS } \\
\text { AS } \\
\text { AS } \\
\text { AS } \\
\text { AS } \\
\text { AS } \\
\text { AS } \\
\text { AS } \\
\text { AS } \\
\text { AS }\end{array}$ & $\begin{array}{l}1 / 47 \\
1 / 47 \\
2 / 47 \\
1 / 47 \\
1 / 47 \\
1 / 47\end{array}$ & $\begin{array}{l}1 / 18 \\
1 / 18 \\
2 / 18 \\
1 / 18 \\
1 / 18 \\
1 / 28\end{array}$ & $\begin{array}{l}\text { Kevin/Merlyn } \\
\text { Dom } \\
\text { Dom } \\
\text { Kevin/Merlyn/Dom } \\
\text { Kevin . } \\
\text { Dom } \\
\text { Ameer }\end{array}$ \\
\hline
\end{tabular}

Figure 2. Sample Thematic Analysis Data

After collecting this data, I turned to comparing it with the popularity of each song. Popularity was determined by data provided by Apple Music, a popular music streaming platform which, as of December 2018, has 58 million users. This number has been increasing at an average of 1 million users per month (Billboard Staff, 2018). Apple Music was qualified for sourcing popularity data because it is used by many users. It also has a popularity ranking for each song an artist releases built into its interface. Apple Music includes a "Top Songs" feature that ranks an artist's songs by streaming popularity. I used this feature to compile the ranking for BROCKHAMPTON's songs.

\section{Observations and Analysis}

To answer my research question, I used two observations from two data sets to answer my research sub-questions first:

\section{a. Does the manner of advocacy — whether it be pro-social or anti-social-have any effect on the pop- ularity of a given song?}

To answer this question, I determined whether each song was pre-dominantly anti-social or prosocial from the thematic analysis data. Then, I compared this factor to the song's popularity. To determine if a song was pre-dominantly anti-social or pro-social, I turned to the $\left(\frac{x}{\# \text { of identified themes }}\right)$ value in the numeric data. This value expressed how concentrated a given theme was when compared to the other social themes. The count for total anti-social themes and total pro-social themes were compared to see which had the greater amount. Songs with a greater amount of prosocial themes are denotated with a green dot, red dots are anti-social, and grey dots are neutral, meaning they have the same number of anti-social and pro-social themes. The following chart represents a relationship between song number and raking, the $\mathrm{x}$ and $\mathrm{y}$ axis, respectively. The song number is the order in which the song appears in the 
SATURATION trilogy, with song "HEAT" assigned song number 1, "GOLD" assigned song number 2, and so on, making it a rudimentary number. Slope is not a negligible factor in this graph.

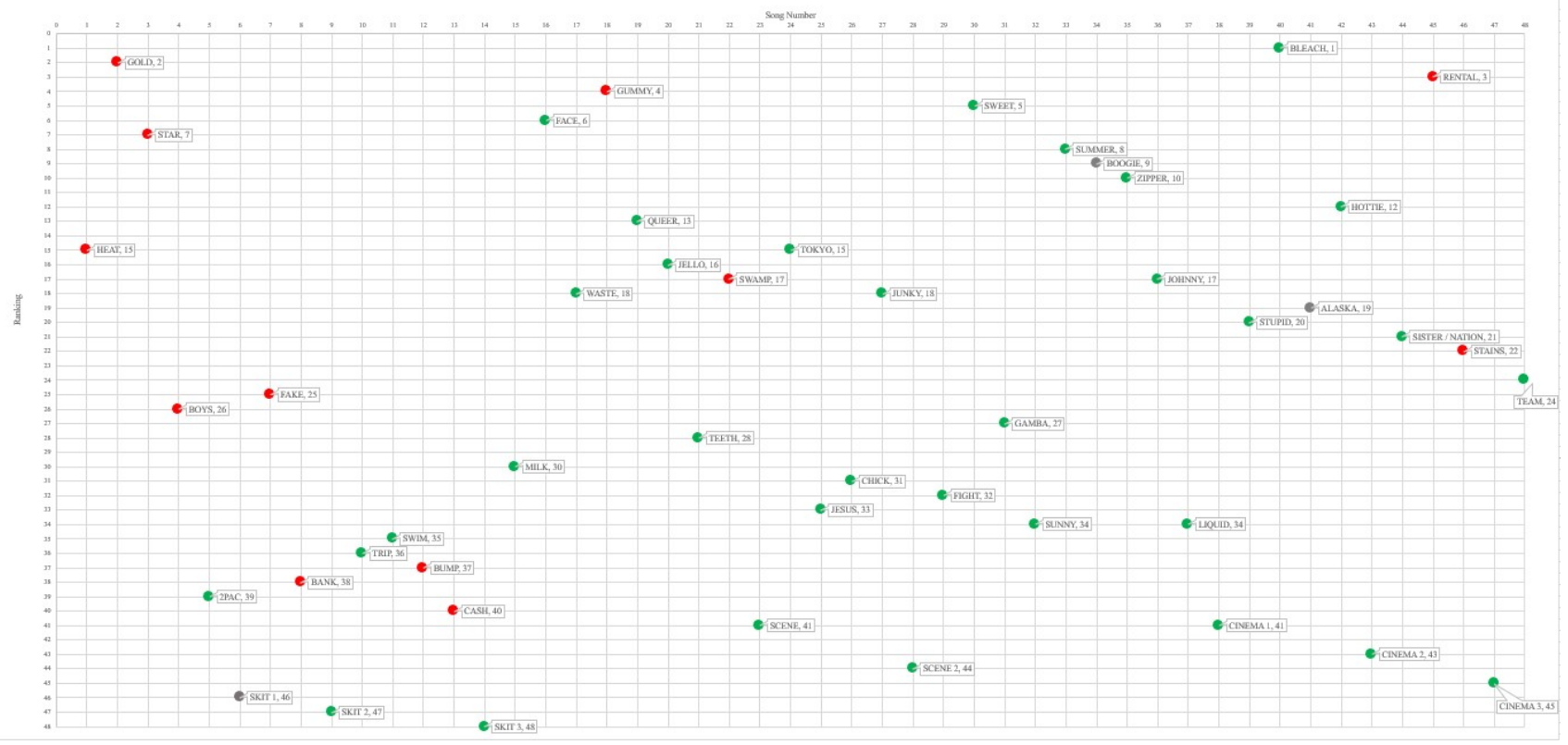

Figure 3. Graph Comparing Popularity and Thematic Category

The SATURATION trilogy is predominantly pro-social. To determine if there was any correlation between thematic content and popularity, I divided the graph into three equivalent popularity ranking ranges. These ranking ranges are areas 1, 2, and 3 on the figure below, divided by rankings 1-16, 17-32, and 33-48 respectively, where ranking \#1 is the most popular and ranking \#48 is the least. Then, I compared how many of each thematic category was represented in each region.

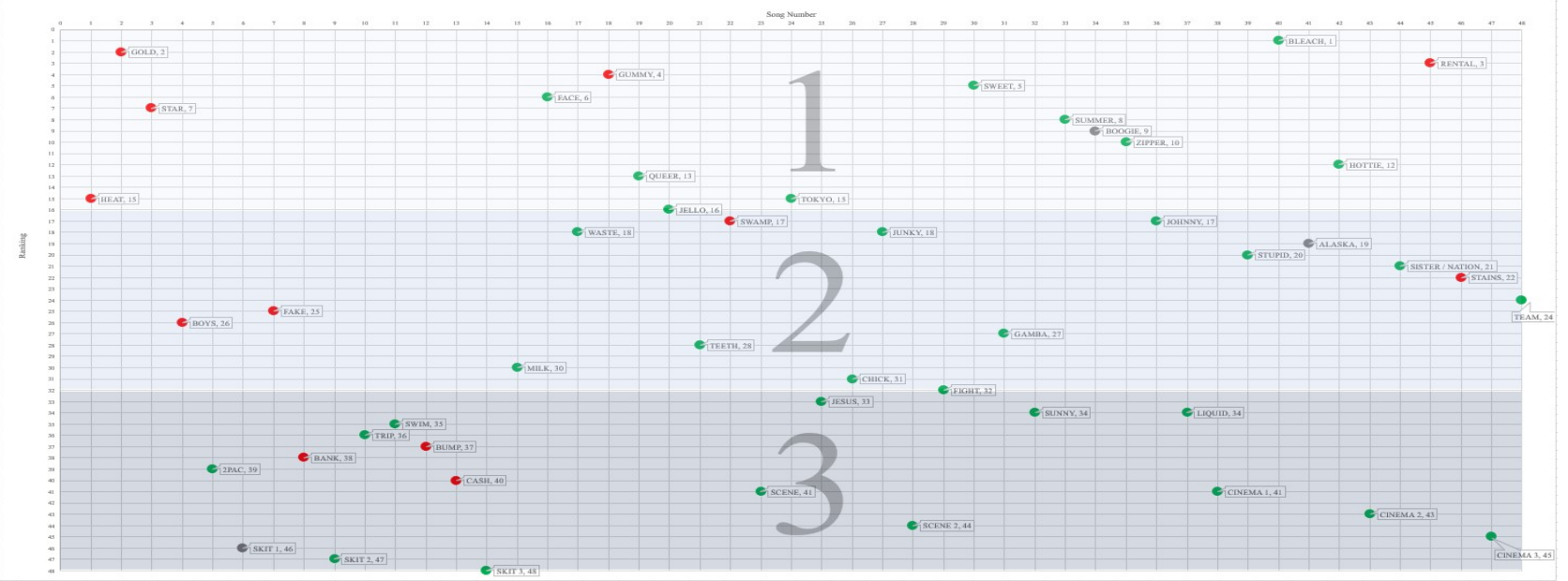

Figure 4. Graph Comparing Popularity and Thematic Category with Popularity Ranking Regions 
To evaluate the proportions of the thematic categories in each region, I calculated $\hat{p}$ (p-hat), the standard deviation of all sample proportions for each one, where, $\hat{p}=\sqrt{\frac{p(1-p)}{n}}$, and variable $\mathrm{p}$ equals the proportion in the category of interest and variable $\mathrm{n}$ is the sample size (University of Florida Health, 2019).

Table 2. $\hat{p}$ Values of Each Region and Thematic Category

\begin{tabular}{|c|c|c|c|c|c|}
\hline & $\begin{array}{l}\text { Mean Proportion } \\
=\left\{\left(\frac{n}{-}\right) \frac{1}{-}\right\}\end{array}$ & $\hat{p}$ of mean & $\hat{p}$ of Region 1 & $\hat{p}$ of Region 2 & $\hat{p}$ of Region 3 \\
\hline Anti-Social & $\frac{4}{12}$ & $\begin{array}{l}\hat{p}=\sqrt{\frac{\frac{4}{12}\left(1 \frac{4}{12}\right)}{12}} \\
=1.36\end{array}$ & $\begin{array}{l}\hat{p}=\sqrt{\frac{\frac{5}{12}\left(1 \frac{5}{12}\right)}{12}} \\
=1.42\end{array}$ & $\begin{array}{l}\hat{p}=\sqrt{\frac{\frac{4}{12}\left(1 \frac{4}{12}\right)}{12}} \\
=1.36\end{array}$ & $\begin{array}{l}\hat{p}=\sqrt{\frac{\frac{3}{12}\left(1-\frac{3}{12}\right)}{12}} \\
=1.5\end{array}$ \\
\hline Pro-Social & $\frac{11.3}{34}$ & $\begin{array}{l}\hat{p}=\sqrt{\frac{\frac{11.3}{34}\left(1-\frac{11.3}{34}\right)}{34}} \\
=.08\end{array}$ & $\begin{array}{l}\hat{p}=\sqrt{\frac{\frac{9}{34}\left(1 \frac{9}{34}\right)}{34}} \\
=.075\end{array}$ & $\begin{array}{l}\hat{p}=\sqrt{\frac{\frac{11}{34}\left(1 \frac{11}{34}\right)}{34}} \\
=.08\end{array}$ & $\begin{array}{l}\hat{p}=\sqrt{\frac{\frac{14}{34}\left(1 \frac{14}{34}\right)}{34}} \\
=.084\end{array}$ \\
\hline Neutral & $\frac{1}{3}$ & $\begin{array}{l}\hat{p}=\sqrt{\frac{\frac{1}{3}\left(1-\frac{1}{3}\right)}{3}} \\
=.27\end{array}$ & $\begin{array}{l}\hat{p}=\sqrt{\frac{\frac{1}{3}\left(1-\frac{1}{3}\right)}{3}} \\
=.27\end{array}$ & $\begin{array}{l}\hat{p}=\sqrt{\frac{\frac{1}{3}\left(1-\frac{1}{3}\right)}{3}} \\
=.27\end{array}$ & $\begin{array}{l}\hat{p}=\sqrt{\frac{\frac{1}{3}\left(1-\frac{1}{3}\right)}{3}} \\
=.27\end{array}$ \\
\hline
\end{tabular}

Using the principles of standard deviation, a normal distribution with no particular skew of data should have at least $65 \%$ of the data - in the context of this study, the $p^{\wedge}$ values of two regions-within one standard deviation of the mean (Standard Deviation, 2020). All of the data is within one $p^{\wedge}$ value of the mean (the second column) with respect to the mean (the first column), meaning that there is no skew of any of the thematic categories towards a particular popularity region. Therefore, there is no strong relationship between thematic content and popularity.

After addressing this question, I turned to my second sub-question of inquiry:

\section{b. Is there any correlation between the manner of advocacy performed in a song and the race that performs it?}

This sub-question intends to incorporate race into the main research inquiry by examining if the usage of a given thematic category by a given BROCKHAMPTON member has any relation with the race of the artist performing it. The race of each performing artist in BROCKHAMPTON is in the following table:

Table 3. Race of each member that performs in BROCKHAMPTON's SATURATION trilogy

\begin{tabular}{ll}
\hline Name & Race \\
\hline Kevin Abstract (Ian Simpson) & African American \\
Joba (Russel Boring) & Caucasian \\
Matt Champion (Matthew Champion) & Caucasian \\
Ameer Vann & African American \\
Dom McLennon & African American \\
Bearface (Ciarán McDonald) & Caucasian \\
Merlyn Wood & African American \\
Roberto (played by Robert Ontenient) & Hispanic
\end{tabular}

To determine trends within which artist contributed to each theme the most—-the "Main Artist" column in the table below-I turned to the "Main artist behind" thematic analysis data. The race of the artist that contributed to a given theme the most was noted in the "Artist Race" column in table 4. 
Table 4. Race to Social Theme Attributions

\begin{tabular}{lll}
\hline Theme & Main Artist & Artist Race \\
\hline Pro-social & & \\
Critique of Racism & Ameer & African American (AA) \\
Gratitude & Kevin & African American \\
Mental Health Awareness & Dom & African American \\
Religion and Spirituality & Ameer & African American \\
Emotional Expression & Dom & African American \\
Political Engagement & Ameer & African American \\
Building Community Unity & Kevin & African American \\
Critique of Oppressive Institutions & Ameer/Dom & African American \\
Female Education & & \\
LGBTQ+ Awareness & Kevin & African American \\
Rape Culture Awareness & Matt & Caucasian (C) \\
Anti-social & & \\
Criminal Activity (General) & Ameer & African American \\
Gang Activity & Ameer & African American \\
Illegal Drugs & Ameer & African American \\
Sexual Objectification of Women & Matt & Caucasian \\
Derogatory Words in ref. to Women & Matt & Caucasian \\
Materialism (General) & Kevin & African American \\
Bragging about Money & Kevin/Matt & AA/C \\
Mentioning Materialistic Items & Kevin/Ameer & African American \\
Bragging about Properties and Assets & Ameer & African American \\
Pro-Attitude towards Materialism & Ameer & African American \\
Mentions of Sexualized Body Parts & Merlyn & African American \\
Sexual Explicitness (General) & Matt & Caucasian \\
Words used to describe Lewd Acts & Matt & Caucasian
\end{tabular}

The theme "Female Education" could not be attributed to a member because it was not mentioned in the trilogy. If a theme has been attributed to two separate members, for example, "Critique of Oppressive Institutions", then two members have been attributed as the main artist of that theme an equal number of times. Both of their races have been noted.

Overall, BROCKHAMPTON's African American performers were attributed to most of the themes, whether pro-social or anti-social.

Table 5. Percent Attributions by Thematic Category and Race

\begin{tabular}{lll}
\hline Race & Anti vs. Pro Social & Percent Attributed \\
\hline African American & Anti-Social & $64.28 \%$ \\
Caucasian & Anti-Social & $35.72 \%$ \\
African American & Pro-Social & $90.9 \%$ \\
Caucasian & Pro-Social & $9.1 \%$
\end{tabular}


Any thematic content discussed in the SATURATION trilogy was predominately performed by an African American. As for BROCKHAMPTON's Caucasian performers, they were attributed to more anti-social themes than pro-social themes. This poses a new point for continued discussion. This is not to say that this displays anti-social themes being dominated by Caucasian artists. Overall, there is no skew of African American performers or Caucasian performers towards one type of social theme. However, the vast number of social themes being attributed to African American performers suggests a newfound relationship; no matter the thematic category, performers who chose to utilize social themes were predominately African American.

Using these two conclusions, I could answer my main research inquiry:

To what extent does the race of a BROCKHAMPTON member and the advocacy they utilize, whether it be pro-social or anti-social advocacy examined through the usage of corresponding social themes, influence the popularity of a given song from BROCKHAMPTON's SATURATION trilogy?

The race of a BROCKHAMPTON member and the advocacy they utilize influences the popularity of a given song from the SATURATION trilogy to a minor extent. Answering the second research question revealed that there is no strong correlation between the type of theme and the race that performs it, other than the fact that most thematic content was contributed to by African American performers, no matter the thematic category. The first research question investigated popularity: even though the SATURATION trilogy is predominately pro-social, there is no correlation between popularity and the thematic category a song belongs to. Even though it is important to consider that most of the social themes are contributed to by African American performers, it is evident that thematic content—and consequently, the race that contributed to it—has little effect on popularity.

\section{Discussion}

Originally, I hypothesized that race and thematic content would affect the popularity of a song to a great extent. Through answering the research inquiry, it is evident that the newfound understanding generated by this study, that thematic content and race has little effect on popularity, refutes the initial hypotheses. This finding, one, helps create a better understanding of the popularity of anti-social versus pro-social rap and two, helps better inform the evolution of the American color line in music marketing and how it affects diverse rap groups.

The findings of this study provide a new grasp on the impact of thematic content in the academic sphere. By finding no correlation between popularity and thematic content within BROCKHAMPTON's SATURATION trilogy, this study both corroborates and refutes the findings of other researchers. This study refutes the findings of researchers like the aforementioned Epps and Dixon, who found that the most popular songs on Billboard Charts, a music popularity chart, were less diverse in terms of thematic content (Epps \& Dixon, 2017 p. 487). This study found that the most popular songs were as diverse in terms of thematic content as the less popular songs. However, this study also concurs with the findings of researchers like Pinn, who asserts that the success of Hip-Hop and the advocacy within it is always unknown, no matter the content. Just as Pinn concludes, the popularity of the songs within BROCKHAMPTON's SATURATION trilogy is not affected by its content (Pinn, 1999). This finding expresses both a continuity and a change in the academic understanding of raps thematic content.

Through this study, I hoped to garner a better understanding of the impact of racial diversity in Hip-Hop. Within the context of BROCKHAMPTON, the races behind the themes that are chosen, albeit predominately African American, are not bound to one thematic category. The BROCKHAMPTON members and the themes they choose to discuss are not bound by popularity influencing, racially defined credibility. This alludes to a change in the content matter diverse rap groups have chosen to discuss - corroborating the findings of researchers like Gallagher, who found that the racial barriers in Hip-Hop are dissolving (Gallagher, 2003). However, in the SATURATION trilogy, Caucasian members were attributed to less pro-social themes than antisocial themes; Caucasian members were attributed to $9.1 \%$ of pro-social themes and $35.72 \%$ of anti-social themes. The fact that Caucasian members performed more anti-social 
themes than pro-social themes-and vice versa for their African American counterpart-could be a product of preference on either the African American member's or the Caucasian member's part. This was not examined in this study. However, studying this could garner a better understanding of how the American color line affects the content artists choose to perform. Moreover, the disparity between the number of anti-social and pro-social themes attributed to Caucasian artists poses one of the few correlations found within this study; out of the few themes Caucasian artists were attributed to, the themes were predominately anti-social. Yet, because of the lack of correlation between theme type and popularity, this correlation cannot expand to answer the larger research question, nor can it fill the gap in knowledge.

Through the discussion of this study's findings and answering the question of inquiry, it is evident that this study does not present a solution to the disposal of the positive, advocating side of Hip-Hop in media. Rather, this study presents a resolution; this study calls for change in the way Hip-Hop is regarded and researched academically. In a world where media, music, and culture are everchanging, research must consider bodies of Hip-Hop works-like albums and discographies - with ambiguity between pro-social and anti-social. Not only this, but Research must also consider the factors that intersect with Rap and Hip-Hop, especially race. By reforming the methods in which HipHop is researched, a better understanding of advocacy in Hip-Hop can be reached. Then, this newfound understanding can be gradually applied to the understanding of the genre in media. This study found a newfound understanding within the SATURATION trilogy; the following section clarifies the limitations and implications of my newfound acumen.

\section{Limitations, Implications, and Conclusion}

First, it is critical to note that within the context of this study, the lyrics of the SATURATION trilogy are viewed as a vessel for social themes. Whether or not a performer chooses to include a social theme in the lyrics they perform is a choice that they make. This assertion can be used to explain the intent of the race data. The intent of this data is to emphasize the choice of the members to include these themes, and if their usage of a given thematic category has any correlation with their race. Even though BROCKHAMPTON has more African American members than Caucasian members, the focus is on what themes an artist chooses to perform. Therefore, this unequal ratio was not a factor I chose to consider in this study.

My findings and analysis only intend to explore the content of the lyrics from the SATURATION trilogy and its correlation with popularity. This study does not consider other factors-for example, musical sound, media traction, music videos, and artist promotions-- and their correlation with popularity. Along with this, my study used one set of popularity data. If this study were to be replicated using another source of popularity data, the results could be different.

When examining the content of the lyrics, I used the aforementioned guidelines to eliminate the analysis of symbolism in the lyrics. This is not to say that there is no symbolism in the content of the trilogy. However, I chose not to analyze symbolism because of ambiguity of personal interpretation. If this study were to be replicated with the analysis of symbolism, the results could vary. Along with this, limiting the social themes that could be identified in the lyrics also limited the results I received. If this study were to be replicated with a different selection of themes or with more self-generated themes, the results could vary.

Lastly, this study only examines the rap group BROCKHAMPTON, which limits the results of this study to the context of BROCKHAMPTON. However, I believe that the methodology I used in this study could be applied to garner a better understanding of another rap group or multiple rap groups. However, my findings can only suggest more about BROCKHAMPTON.

As I continue to listen and digest Hip-Hop daily, I will be constantly reminded of its implications and influence. While I understand that media and culture may not explore Hip-Hop to the extent that researchers like myself do, I know that the potential is there, waiting to be tapped into. Whether that potential is positive, or negative is up for the artist to decide, but nonetheless, the potential will persist. 


\section{References}

Advocacy. (2020). Retrieved from https://www.merriam-webster.com/dictionary/advocacy

Alridge, D. P. (2003). HIP HOP VERSUS CIVIL RIGHTS? The Journal of African American History, 88(3), 313-

316. Retrieved from http://ezproxy.kcls.org/login?url=https://search.proquest.com/docview/194460840?acountid=46

Barretta, P. G. (2017). Tracing the color line in the american music market and its effect on contemporary music marketing. Arts Marketing, 7(2), 213-234. doi:http://dx.doi.org/10.1108/AAM-08-2016-0016

Billboard. (2020, January 24). BROCKHAMPTON Chart History. Retrieved January 31, 2020, from https://www.billboard.com/music/brockhampton/chart-history

Billboard Staff. (2018, December 3). Apple Music Now Has 56 Million Users: Report. Retrieved from https://www.billboard.com/articles/business/8487726/apple-music-56-millionusers-report

Blum, A. (2016). Rhythm Nation. Studies in Gender \& Sexuality, 17(3), 141-149.

https://doi.org/10.1080/15240657.2016.1199923

Conrad, K., Dixon, T., \& Zhang, Y. (2009). Controversial Rap Themes, Gender Portrayals and Slan Tone Distortion: A Content Analysis of Rap Music Videos. Journal of Broadcasting \& Electronic Media, 53(1), 134-156. https://doi.org/10.1080/0883-8150.80.2.643

Dunbar, E. (2007). Deconstructing tyrone: A new look at black masculinity in the hip-hop Generation/From black power to hip hop: Racism, nationalism, and feminism. Callaloo, 30(4), 1114-1117,1127. Retrieved from http://ezproxy.kcls.org/login?url=https://search.proquest.com/docview/233174824? accountid=46

Epps, A. C., \& Dixon, T. L. (2017). A Comparative Content Analysis of Anti- and Prosocial Rap Lyrical Themes Found on Traditional and New Media Outlets. Journal of Broadcasting \& Electronic Media, 61(2), 467-498. https://doi.org/1080/08838151.2017.1309411

Gallagher, C. A. (2003). COLOR-BLIND PRIVILEGE: THE SOCIAL AND POLITICAL FUNCTIONS OF ERASING THE COLOR LINE IN POST RACE AMERICA. Race, Gender \& Class, 10(4), 22. Retrieved from http://ezproxy.kcls.org/login?url=https://search.proquest.com/docview/218849664? accountid=46

Genius Media Group Inc.. (2020). About Genius. Retrieved February 20, 2020, from https://genius.com/Geniusabout-genius-annotated

Hemnani, R., Merlyn, K., Manwa, J., \& Gomez, R. (Producers), \& Wood, W., \& Merriweather, I. (2017). SATURATION II [Recorded by R. Boring, I. Simpson, M. Champion, M. Wood, C. McDonald, D. McLennon, ... R. Beatty] [Audio tape]. Brockhampton, Empire. Submit

Hemnani, R., Merlyn, K., Manwa, J., \& Gomez, R. (Producers), \& Wood, W., \& Merriweather, I. (2017). SATURATION III [Recorded by R. Boring, I. Simpson, M. Champion, M. Wood, C. McDonald, D. McLennon, ... R. Beatty] [Audio tape]. Brockhampton, Empire. Submit 
Hemnani, R., Merlyn, K., Manwa, J., \& Gomez, R. (Producers), \& Wood, W., \& Merriweather, I. (2017). SATURATION [Recorded by R. Boring, I. Simpson, M. Champion, M. Wood, C. McDonald, D. McLennon, ... R. Beatty] [Audio tape]. Brockhampton, Empire.

Jenkins, C. (2018, Nov 26). Brockhampton Isn't your typical 13-member rap collective: Brockhampton is not your typical 13-member genre-defying rap collective-slash- multimedia empire. New York, Retrieved from http://ezproxy.kcls.org/login?url=https://search.proquest.com/docview/2187603633?accountid=46

Mathus, P. (2018, Feb 12). BROCKHAMPTON: ART + CULTURE. University WireRetrieved from http://ezproxy.kcls.org/login?url=https://search.proquest.com/docview/2001175596?accountid=46

McLeod Jr., J. D. (2017). If God Got Us: Kendrick Lamar, Paul Tillich, and the Advent of Existentialist Hip Hop. Toronto Journal of Theology, 33(1), 123-135. https://doi.org/10.3138/tjt.2017-0006

Miller, M., Hodge, D. W., Coleman, J., \& Chaney, C. D. (2014). The hip in hip hop: Toward a discipline of hip hop studies. The Journal of Hip Hop Studies, 1(1), 6-12. Retrieved from http://ezproxy.kcls.org/login?url=https://search.proquest.com/docview/1503127052?accountid=46

Pinn, A. B. (1999). "How ya livin'?": Notes on rap music and social transformation.Western Journal of Black Studies, 23(1), 10-21. Retrieved from http://ezproxy.kcls.org/login?url=https://search.proquest.com/docview/200354113?accountid=46

Rutherford, C. D. (2005). "GANGSTA" CULTURE IN A POLICED STATE: THE CRISIS IN LEGAL ETHICS FORMATION AMONGST HIP-HOP YOUTH. National Black Law Journal, 18(2), 305-340. Retrieved from http://ezproxy.kcls.org/login?url=https://search.proquest.com/docview/194250186?accountid=46

SpanishDict. (2020). Retrieved February 21, 2020, from https://www.spanishdict.com/

Standard Deviation. (2020). Retrieved May 17, 2020, from https://www.robertniles.com/stats/stdev.shtml

Travis, R. (2013). Rap Music and the Empowerment of Today's Youth: Evidence in Everyday Music Listening, Music Therapy, and Commercial Rap Music. Child \& Adolescent Social Work Journal, 30(2), 139-167. https://doi.org/10.1007/s10560-012-0285-X

University of Florida Health. (2019, September 16). Sampling Distribution of the Sample Proportion, p-hat. Retrieved from https://bolt.mph.ufl.edu/6050-6052/module9/sampling-distribution-of-p-hat/ 